\title{
O LUGAR E A IMPORTÂNCIA DA FILOSOFIA NA FORMAÇÃO
} DOCENTE

\section{THE PLACE AND IMPORTANCE OF PHILOSOPHY IN THE TEACHER'S GRADUATION}

\author{
Valter Ferreira Rodrigues ${ }^{1}$ \\ Maria Dayanny Goncalves ${ }^{2}$ \\ Amanayara Raquel de Sousa Ferreira ${ }^{3}$
}

Recebido em: 05/2018

Aprovado em: 07/2018

\begin{abstract}
Resumo: $\mathrm{O}$ presente texto se baseia no primeiro momento de uma pesquisa que está em desenvolvimento no Centro de Formação de Professores da Universidade Federal de Campina Grande, no âmbito do Programa Institucional de Bolsas de Iniciação Científica e que se destina ao estudo acerca da importância e das contribuições do estudo da Filosofia nos cursos de Licenciatura do CFP, a fim de verificar como a Filosofia colabora na formação dos graduandos, em especial dos futuros professores e professoras da educação básica. Numa primeira vigência (2017-2018), a pesquisa concentrou-se num estudo bibliográfico-documental sobre essa temática e nesse texto traz algumas considerações acerca do papel da universidade na sociedade atual, desde algumas considerações sobre a análise desenvolvida por Boaventura Santos e reflete a importância de considerar no ensino filosófico aquilo que chama de uma Filosofia para não filósofos.
\end{abstract}

Palavras-chaves: Ensino de Filosofia. Ensino Superior. Licenciatura.

\begin{abstract}
The present text is based in the first part of a research that is under development in the Training Center of Teachers of the Federal University of Campina Grande, within the scope of the Institutional Program of Scientific Initiation Scholarships, which is intended to study the importance and contributions of the study of Philosophy in the Graduation courses in the CFP, in order to verify how the Philosophy collaborates in the formation of the graduating ones, especially for basic education teachers formation. In a first period (2017-2018), the research concentrated on a bibliographical-documentary study on this subject and in this text brings some considerations about the university's role in the current society, from some considerations on the analysis developed by Boaventura Santos and reflects on a way the importance of considering in philosophical teaching what he calls a Philosophy for non-philosophers.

Key-words: Teaching Philosophy. College Formation. Graduation.
\end{abstract}

\footnotetext{
${ }^{1}$ Universidade Federal de Campina Grande. Email: valterfilosofia@superig.com.br

${ }^{2}$ Universidade Federal de Campina Grande. Email: dayannygoncalvess@gmail.com

${ }^{3}$ Universidade Federal de Campina Grande. Email: amanayarasousa_@hotmail.com
} 


\section{Filosofia para não-filósofos}

Há algum tempo, o ensino de Filosofia, na perspectiva da prática do filosofar, tem sido objeto de nossas reflexões e a pesquisa que apresentaremos ao longo desse texto dá sequência a uma série de estudos que temos empreendido desde 2010 acerca dessa temática. Recentemente nos voltamos para a Filosofia no ensino superior, perguntando pelo lugar e a importância da Filosofia nas diversas graduações, em especial, nos cursos de licenciatura. O presente artigo faz parte de um estudo ainda em desenvolvimento no Centro de Formação de Professores (CFP), da Universidade Federal de Campina Grande, campus de Cajazeiras (PB), no âmbito do Programa Institucional de Bolsas de Iniciação Científica (PIBIC), cujo principal objetivo é avaliar a importância e as possíveis contribuições da Filosofia na formação dos discentes das licenciaturas no referido campus.

Prevista, inicialmente, para duas vigências, a primeira etapa da pesquisa compreende um amplo estudo bibliográfico-documental que visa não apenas elucidar a situação do ensino de Filosofia na universidade e as possíveis contribuições desta à formação dos futuros professores (através da análise de literatura especializada no assunto, marcos legais, planos e programas dos cursos), mas, também refletir sobre outras questões acerca da situação atual do ensino superior no país e do modo como afeta a realidade local. Em tempos de revisões curriculares, elaboração de novos e outros projetos pedagógicos, quando a própria Universidade se vê tendo de dar explicações acerca de sua própria existência e finalidade, seu lugar, sua utilidade e importância não são questões que devem ser postas de lado ou esquecidas ou perigosamente ignoradas. Entendemos que a pergunta pela importância da Filosofia não diz respeito apenas a uma determinada disciplina disposta "assim ou assado" nas grades curriculares dos cursos. É antes de tudo a pergunta por um tipo de saber que, pelo menos em tese, não está subordinado a modelos instrumentalizados do conhecimento, por vezes mais desejados por causa de sua pretensa eficácia pragmática e rentabilidade econômica. A pergunta pela importância da Filosofia diz respeito a todo um modo de compreender o uso da razão, que há tempos converte-se em racionalidade tecnicista, que a tudo e todos coisifica, manipula, aliena e explora em nome de causa alguma e que se mostra nas formas de um niilismo cultural e anomia ética, naquilo que alguns pensadores chamaram de crise civilizacional. Trata-se de perguntar pelo espaço e necessidade da Filosofia em modelos de formação acadêmica baseados na busca de resultados e oferta de produtos econômicos do conhecimento. Finalmente, 
empreender uma pesquisa sobre o ensino de Filosofia nas licenciaturas, diz respeito aos benefícios desse ensino à prática docente e à vida acadêmica como um todo.

Assim como acontece no ensino médio, a filosofia que é apresentada aos nossos estudantes dos cursos de Licenciatura é uma filosofia majoritariamente acadêmica, universitária, "superior", cujo acesso demanda, por exemplo, uma necessária base escolar que a maior parte da população não possui, na forma de competências de leitura, interpretação e escrita, além de alguns conhecimentos prévios, como, por exemplo, no campo da História e da Geografia. Todavia, o maior problema está em tornar o ensino de filosofia em uma transcrição adaptada do tipo de ensino ofertado na universidade, fortemente voltada à transmissão de conteúdos "filosóficos", quer sejam temáticos quer sejam históricos e que acaba por dar continuidade àquilo que Foucault chamou de "formalização do pensamento" (1999, p. 480). Alertamos para um tipo de ensino da Filosofia que não é capaz de promover uma educação filosófica (CARVALHO, 2017), uma vez que paralisa o pensamento, homogeneíza e o mantém fechado e subordinado aos ditames pré-estabelecidos da academia. Aproveitando a inflexão proposta por Gallo (2008), que em Deleuze e a Educação, lança mão dos termos "maior" e "menor" para criticar um tipo de versão oficial de ensino, uma educação "maior" sob a custódia dos interesses do Estado, é possível inferir que algo semelhante também ocorre com a filosofia que se ensina e uma "filosofia maior" prepondera em nossas práticas e compreensão docentes. Deleuze ao tratar da noção de "imagem do pensamento", vai falar da necessidade de uma "nãofilosofia" que se apresenta como uma linha de fuga frente uma imagem clássica do pensamento (pensamento representativo). Entra em cena uma filosofia diferente, ou melhor, uma filosofia da diferença e que só possível na diferença, em nossa abordagem entendida como uma filosófica não escolar e até não acadêmica.

Pensar a Filosofia para não-filósofos é, ao mesmo tempo, uma oportunidade e um desafio, em função da realidade na qual estamos inseridos, uma vez que falamos desde um campus onde não há curso de Filosofia e onde disciplinas filosóficas, mormente introdutórias, acham-se aqui e ali dispersas. Todavia, um cenário que poderia ser muitas vezes visto como desfavorável ao exercício do filosofar converte-se em oportunidade para o pensamento que é por natureza errante e criativo. Por causa de sua trajetória, no CFP, as questões da Educação estão entre as que mais nos fazem filosofar. Lá encontramos um lugar propício para uma Filosofia da Educação. Como veremos no tópico a seguir, a UFCG e a cidade de Cajazeiras têm um longo histórico com a educação na Paraíba e isso se deve não apenas pelo número de cursos 
de Licenciatura que são ofertados no centro, mas, especialmente por sua história. A exemplo de outras instituições, na história da fundação e consolidação do CFP, encontramos também a presença da Filosofia.

\section{O lócus da pesquisa: uma perspectiva histórica}

O lócus da nossa pesquisa sobre o ensino de Filosofia é o Centro de Formação de Professores (CFP) que atualmente é definido como o Campus II da Universidade Federal de Campina Grande (UFCG), localizado na cidade de Cajazeiras, interior da Paraíba. Hoje o CFP conta com nove cursos de Licenciatura: História (matutino e noturno), Geografia (matutino e noturno), Pedagogia (matutino e noturno), Letras-Português (matutino e noturno), Letras-Inglês (matutino e noturno), Física (noturno), Matemática (matutino e noturno), Química (noturno), Ciências Biológicas (matutino), e dois cursos de Bacharelado: Enfermagem e Medicina, além dos cursos de nível técnico que ocorrem conjuntamente com o Ensino Médio.

O CFP passou por conjunturas importantes desde a sua criação que marcam sua caracterização atual em vários aspectos. No ano de 1979, ainda no contexto da Ditadura Militar, foi criada a primeira universidade federal de Cajazeiras - PB por meio da Resolução 62/79, o Campus V da Universidade Federal da Paraíba é criado a partir da federalização da FAFIC (Faculdade de Filosofia, Ciências e Letras) empreendida pelo Cônego Luiz Gualberto (FILHO, 2015, p.28).

De acordo com o Relatório de Atividades (1980-1984) do Prof. Ms. José Antônio de Albuquerque, primeiro diretor do CFP, o campus nesse período da década de 1980 dispunha de seis Licenciaturas, que eram: História, Geografia, Letras, Pedagogia, Ciências, Matemática e um curso técnico em Enfermagem. Também percebemos no documento a presença de dois cursos de Licenciatura de $1^{\circ}$ Grau, a de Estudos Sociais e a de Ciências, esse tipo de curso que pode ser chamado de Licenciatura Curta é uma característica marcante do contexto histórico da política de educação nessa época de Ditadura Militar (1964-1985) no País.

Depois de sua criação, ainda numa perspectiva estrutural, já no século XXI o CFP passa por outro momento marcante em sua história, no ano de 2002 quando ocorre o desmembramento do Campus V da UFPB, se tornando a partir daí o Campus II da Universidade Federal de Campina (UFCG) por meio da sanção da Lei Federal no 10.419 (09 de abril de 2002). 
Em 2009, após 30 anos de sua fundação, o CFP fez a primeira reformulação em sua grade curricular, com muitas discussões sobre a estrutura dos cursos, assim realizando importantes alterações nas disciplinas, inclusive com a implantação da disciplina TCC (Trabalho de Conclusão de Curso) na maioria dos seus cursos.

Em 2012, também houve uma reforma nesse âmbito, porém, destinada à área das Ciências Naturais. O curso de Licenciatura em Ciências se extingue desmembrando-se nos cursos de Licenciatura Plena em Física, Química e Ciências Biológicas.

Perceber todas essas transformações é um ato de suma importância para a nossa pesquisa, tendo em vista conhecer a presença e o formato da Filosofia nesses cursos. Com esse desmembramento na área das Ciências Naturais pode-se inferir que houve um maior alcance da Filosofia, se pensar que anteriormente havia apenas um único curso, o de Ciências, com suas habilitações para cada disciplina específica. Com o desmembramento, foram criados três novos cursos, cada um deles com, pelo menos, uma disciplina no currículo.

Sabemos que o curso de Filosofia propriamente dito, o CFP, ao longo de sua história como instituição de ensino superior, não ofertou. Porém, sua presença se nota através de disciplinas como "Introdução a Filosofia" e "Fundamentos do Pensamento Filosófico" que estão na grade curricular dos cursos de Licenciatura e atualmente também nos bacharelados existentes no Campus. Há ainda as disciplinas de Introdução à Medicina, que é dividida em módulos, sendo um deles dedicado ao estudo da Ética. No curso de Enfermagem os discentes estudam Antropologia Filosófica I e II, portanto, em dois períodos. Na Licenciatura em Pedagogia, além da disciplina de Introdução à Filosofia há também as de Filosofia da Educação I e II (três semestres ao todo de disciplinas filosóficas). E por fim, ainda há outras disciplinas filosóficas mais “específicas”, como, por exemplo: filosofia da educação matemática e filosofia da ciência. Em geral, a maior parte dessas disciplinas são de 60 horas-aula (4 créditos). A menor carga horária que registramos está no módulo de ética, da disciplina de Introdução à Medicina, única disciplina filosófica do curso, com 30 horas aulas.

\section{A universidade hoje à luz do pensamento de Boaventura Santos: breves considerações}

Desde o surgimento das universidades, sua finalidade e o conhecimento por elas produzido vêm mudando continuamente anos após ano. Tais mudanças se dão a partir de interesses, desenvolvimento econômico, crises e desafios, postos cotidianamente à sociedade e 
que acabam atingindo consequentemente, também a universidade. Tais mudanças aconteceram com o desenvolvimento do capitalismo, a descentralização e falta de investimentos nas políticas sociais, a falta de autonomia da universidade no desenvolvimento de conhecimento, a necessidade de mão de obra qualificada e a incapacidade da própria universidade desenvolver tais tarefas. A universidade pública, até então financiada exclusivamente pelo Estado, é "obrigada" a estabelecer algumas mudanças internas no seu desenvolvimento e outras relações para continuar a existir. Boaventura Santos nos fala de três tipos de crises que a universidade precisou reconhecer e que consubstanciaram tais mudanças: a crise de hegemonia; a crise de legitimidade e, finalmente, a crise institucional.

$\mathrm{Na}$ crise de hegemonia, a universidade que antes era vista como detentora do poder absoluto de formação intelectual, passa a ser descaracterizada como tal por não conseguir atender à necessidade de formação de mão-de-obra qualificada. O não comprimento de tal função leva ao surgimento de novos centros de formação, como a criação de cursos técnicos e universidades privadas.

A crise de legitimidade deriva da desvalorização do diploma universitário e o acesso reduzido de vagas às classes populares. E, por último, há a crise institucional, na qual a universidade perde sua autonomia e passa a ter uma pseudo-autonomia, pois se encontra subordinada à interesses políticos com seus projetos partidários e de empresas, como o Banco Mundial, além de uma crescente falta de investimento do Estado e a descapitalização da universidade pública.

Portanto, a principal mudança decorrente de tais crises foi a transformação do conhecimento em mercadoria e, consequentemente, a mercantilização da universidade.

O Estado passou a estabelecer normas iguais para instituições de caráter público e privado. Esta normatização fez com que a universidade pública procurasse outras formas de se adaptar, para continuar desenvolvendo suas funções formadoras. Ela precisou atender os interesses da economia e, com isso, docentes e pesquisadores, antes responsáveis pela formação intelectual e construção de conhecimento, passaram a desconhecer a formação que os discentes estavam recebendo. A mudança do estudante para o consumidor culminou quando a universidade que em vez de fornecer um ensino gratuito, oferece empréstimos e bolsas remuneradas pela sua formação acadêmica. Há uma incessante e desleal disputa entre as Instituições de Ensino Superior (IES), públicas e privadas. 
Diante de todo conteúdo exposto até este momento, é inegável a relação do modo de desenvolvimento da universidade com o desenvolvimento econômico do país, mais precisamente, com o apoio da indústria. Esta relação é estabelecida como vimos anteriormente, através da necessidade do financiamento das universidades e pela saída de crises financeiras, que a obrigam a procurar financiamentos na iniciativa privada, em decorrência da perda de prioridade de investimentos do Estado. O sistema capitalista passa a atuar como consumidor/destinatário dos serviços prestados pela universidade, o conhecimento produzido na universidade é utilizado na construção e inovação tecnológicas, bem como, desenvolvimento de produtos e de capital para as empresas. De acordo com Santos (2008), a frase, "economia baseada no conhecimento" retrata bem as mudanças recorrentes na universidade e a influência da indústria no desenvolvimento do conhecimento. Diante disto, constatamos que o conhecimento produzido na universidade é utilizado como moeda de troca, que acaba "beneficiando" a indústria e a universidade que necessita do capital gerado. Entretanto, podemos nos perguntar: quais os perigos desta influência sobre a vida acadêmica?

À medida que a universidade permanece com estas relações, seu "corpo" humano tornase alienado e condicionado a obedecer às regras de mercado. Boaventura Santos (2008) aponta que é necessário que a universidade procure e estabeleça outras relações para se desenvolver economicamente, não recorrendo unicamente ao setor privado, limitando assim sua autonomia. Mas, que permita estabelecer e priorizar o conhecimento através de pesquisas, que sejam desenvolvidas por seus discentes e docentes. Deste modo, podemos pensar a importância do ensino da Filosofia no seu mais profundo sentido, no que refere-se à construção do conhecimento crítico, bem como, à formação de sujeitos pensantes. Podemos pensar também no porquê o ensino da Filosofia é “deixado de lado" e posto como não obrigatório na formação dos sujeitos. Seu ensino e seu conhecimento crítico ameaçam o modelo capitalista de ensino?

Para terminar, uma última questão para pensarmos a partir das reflexões de Boaventura Santos. Segundo ele há dois tipos de conhecimentos: um chamado de universitário e outro de pluriversitário. De acordo com seu entendimento, o conhecimento universitário é descontextualizado e homogêneo e atua de maneira oposta ao cotidiano, no sentido de não atender as suas necessidades. Seu desenvolvimento e objetivos são definidos por pesquisadores que defendem que o conhecimento não tem de ter necessariamente relação com as demandas sociais. 
O conhecimento pluriversitário é contextualizado e heterogêneo, isto é, ele é aplicável e dialoga com outros tipos de conhecimento. Sua problemática é fruto de uma partilha entre pesquisadores e utilizadores, portanto, trata-se de um conhecimento transdisciplinar, aberto e atento às demandas sociais.

\section{Referências}

ALBUQUERQUE, J. A. Relatório de Atividades do Diretor do CFP/UFPB. Cajazeiras-PB, 1984. 52pg.

BRASIL. Casa Civil. Lei $\mathbf{N}^{\circ}$ 10.419, de 9 de abril de 2002. Criação da Universidade Federal de Campina Grande - UFCG, a partir do desmembramento da Universidade Federal da Paraíba - UFPB. Brasília,2002. Disponível em: <http://www.planalto.gov.br/ccivil_03/leis/2002/L10419.htm>. Acesso em: 07 de nov. 2015.

CARVALHO, F. Educação filosófica como resistência: considerações iniciais sobre a pedagogia da imaginação como contraconduta. In ALENCAR, M. V. et al. Filosofar e ensinar a filosofar. São Paulo, ANPOF, 2017.

DELEUZE, G.; GUATTARI, F. O que é a filosofia? Tradução Lucia Pereira de LucenaGuerra; Ana Bustamante. Rio de Janeiro: Ed. 34, 2009.

FILHO, J. A. C. Reestruturação urbana de Cajazeiras-PB influenciada pela implantação e expansão do setor de ensino superior. TCC (Licenciatura em Geografia) Universidades Federal de Campina Grande, Cajazeiras: UFCG, 2015.

FOUCAULT, M. As palavras e as coisas: uma arqueologia das ciências humanas. Tradução Salma T. Muchail. 8. ed. São Paulo: Martins Fontes, 1999.

GALLO, S. Deleuze e a educação. 2. ed. Belo Horizonte: Autêntica, 2008.

SANTOS, B. S.; FILHO, N. A. A universidade no século XXI: para uma universidade nova. COIMBRA: [s.n.], 2008.

VÁZQUEZ, A. S. Filosofia da Praxis. 4. ed. Tradução Luiz Fernando Cardoso. São Paulo: Ed. Paz e Terra, 1990. 